\title{
Effect of sevoflurane anesthesia on neuromuscular blockade produced by rocuronium infusion in dogs
}

\author{
Hisashi SAKATA ${ }^{1)}$, Yushun ISHIKAWA ${ }^{1)}$, Genki ISHIHARA ${ }^{2)}$, Norihiko OYAMA ${ }^{1)}$, \\ Takaharu ITAMI ${ }^{1}$, Mohammed Ahmed UMAR $^{3)}$, Tadashi SANO ${ }^{4)}$ and \\ Kazuto YAMASHITA ${ }^{1) *}$ \\ 1)Department of Small Animal Clinical Sciences, School of Veterinary Medicine, Rakuno Gakuen University, \\ Ebetsu, Hokkaido 069-8591, Japan \\ ${ }^{2)}$ Anicom Specialty Medical Institute, Inc., Nishi-Shinjuku, Tokyo 160-0023, Japan \\ ${ }^{3)}$ Department of Veterinary Surgery and Radiology, Faculty of Veterinary Medicine, University of Maiduguri, \\ Maiduguri, Borno State, Nigeria \\ 4)Department of Veterinary Nursing Science, School of Veterinary Medicine, Rakuno Gakuen University, Ebetsu, \\ Hokkaido 069-8591, Japan
}

J. Vet. Med. Sci.

81(3): 425-433, 2019

doi: 10.1292/jvms.18-0479

Received: 13 August 2018 Accepted: 2 January 2019 Published online in J-STAGE: 30 January 2019

\begin{abstract}
This study evaluated the effect of sevoflurane anesthesia on neuromuscular blockade with rocuronium in dogs. Six healthy beagle dogs were anesthetized four times with a minimum 14-day washout period. On each occasion, the dogs were administered 1.25-, 1.5-, 1.75-, or 2.0fold of the individualized minimum alveolar concentration (MAC) of sevoflurane and received an infusion of rocuronium $(0.5 \mathrm{mg} / \mathrm{kg}$ followed by $0.2 \mathrm{mg} / \mathrm{kg} / \mathrm{hr}$ ) for $120 \mathrm{~min}$. Neuromuscular function was monitored with acceleromyography and train-of-four (TOF) stimulation of the left hind limb. Time to achieve TOF count 0 (onset time), time from the onset of neuromuscular blockade to the reappearance of TOF count 4 (blockade period), and time from the onset of rocuronium infusion to attaining a 70 or $90 \%$ TOF ratio $\left(\mathrm{TOFR}_{70}\right.$ or $\left.\mathrm{TOFR}_{90}\right)$ were recorded. There were no significant differences in the onset time, blockade period, and plasma rocuronium concentration between the sevoflurane MAC multiples. The TOFR $\mathrm{T}_{70}$ and $\mathrm{TOFR}_{90}$ were dose-dependently prolonged with the sevoflurane MAC multiples. There were significant differences in the TOFR 70 and TOFR between the 1.25 sevoflurane MAC (median: 55 and 77.5 min, respectively) and 1.75 sevoflurane MAC (122.0 and $122.6 \mathrm{~min} ; P=0.020$ and $P=0.020$, respectively), 1.25 sevoflurane MAC and 2.0 sevoflurane MAC (126.0 and $131.4 \mathrm{~min} ; P=0.020$ and $P=0.020)$, and 1.5 sevoflurane MAC (97.5 and $121.3 \mathrm{~min}$ ) and 2.0 sevoflurane MAC ( $P=0.033$ and $P=0.032)$. In dogs, sevoflurane anesthesia produced dose-dependent prolongation of recovery from neuromuscular blockade produced by rocuronium.
\end{abstract}

KEY WORDS: dog, interaction, neuromuscular blockade, rocuronium, sevoflurane

Rocuronium bromide is a monoquaternary analogue of the bisquaternary aminosteroid pancuronium which was developed to create a non-depolarizing muscular blocking agent (NDMBA) with an onset time and duration of action shorter than those of atracurium or vecuronium [7]. Indeed, a single bolus of intravenous (IV) rocuronium $(0.4 \mathrm{mg} / \mathrm{kg})$ has a relatively low potency with a rapid onset time and an intermediate acting period in dogs [13]. Moreover, a single IV bolus of low-dose rocuronium (0.03 or $0.05 \mathrm{mg} / \mathrm{kg}$ ) was reported to produce short-lasting globe centralization without respiratory depression in dogs [6]. Furthermore, rocuronium may be used more frequently in veterinary clinical practice, as its reversal agent, sugammadex [36], becomes widely available.

Under clinical conditions, rocuronium has been incrementally dosed or infused to maintain an adequate level of neuromuscular blockade in dogs $[1,13]$. Rocuronium is suitable for continuous infusion since it does not produce active metabolites [3]. Compared to incremental dosing regimens, infusions provide greater stability in drug concentration and effect, reduce dosing and cost, and increase safety by promoting rapid recovery [49]. In humans, short-duration rocuronium infusions have not led to drug accumulation [35] and longer infusion durations resulted in only moderately prolonged recovery times [20, 45]. Alderson et al. [1] reported that a constant rate infusion (CRI) of rocuronium $(0.2 \mathrm{mg} / \mathrm{kg} / \mathrm{hr}$ following $0.5 \mathrm{mg} / \mathrm{kg}$ IV infusion) provided effective

*Correspondence to: Yamashita, K.: yamasita@rakuno.ac.jp

O2019 The Japanese Society of Veterinary Science

This is an open-access article distributed under the terms of the Creative Commons Attribution Non-Commercial No Derivatives (by-nc-nd) License. (CC-BY-NC-ND 4.0: https://creativecommons.org/licenses/by-nc-nd/4.o/) 
muscular relaxation for surgical procedures in dogs under isoflurane anesthesia. Rocuronium infusion may become more common in veterinary practice, particularly for prolonged surgeries.

Many factors influence the effect of NDMBAs, and the most important factors are age, physical status, sex, body weight, anesthetic technique, monitoring method [18], body temperature [19], and acid-base differences [26, 39, 40]. During anesthesia, several drugs are used simultaneously. Of these drugs, potent volatile anesthetic agents are known to enhance the magnitude and duration of neuromuscular block $[18,37]$. In recent years, volatile inhalation anesthetics, such as isoflurane and sevoflurane, have been widely used in veterinary practice [46]. These volatile inhalation anesthetics are known to potentiate the effect of NDMBAs $[5,11,25]$. Sevoflurane is used in various animal species to maintain general anesthesia because it has a low blood/ gas solubility coefficient, resulting in rapid induction and recovery from anesthesia [46]. Paul et al. [7] reported that sevoflurane caused dose-dependent inhibition of adult mouse muscle nicotinic acetylcholine receptors (nAChRs) and enhanced neuromuscular blockade produced by NDMBAs in vitro. Moreover, sevoflurane anesthesia has been reported to potentiate the neuromuscular blockade produced by NDMBAs, such as atracurium and vecuronium, in dogs [22, 37]. However, Dugdale et al. [13] reported that premedication, maintenance agent, body position, and stimulation site had no significant influences on the pharmacodynamic parameters of rocuronium when it was administered by a single IV bolus to dogs under clinical conditions. As mentioned above, rocuronium infusion may be used more frequently in veterinary practice for prolonged surgeries. It has been suggested that sevoflurane anesthesia may potentiate the neuromuscular blockade produced by rocuronium infusion. However, no studies have evaluated the interaction between sevoflurane anesthesia and rocuronium infusion in dogs.

The purpose of the present study was to evaluate the effect of sevoflurane on the neuromuscular blockade produced by rocuronium infusion in dogs. We hypothesized that sevoflurane anesthesia would potentiate the neuromuscular blockade produced by rocuronium in a dose-dependent manner in dogs.

\section{MATERIALS AND METHODS}

\section{Experimental animals}

Six adult beagle dogs (two years old, $10.2-12.3 \mathrm{~kg}$, three males and three females) were used for the experiments. The minimum alveolar concentration (MAC) of sevoflurane was determined for each dog using the tail clamp method [50] one month prior to the experiments. The dogs were judged to be in good to excellent health based on physical examination, blood cell counts, and serum biochemical profiling. We used the same number of female and male dogs to offset sex differences. The dogs were cared for according to the principles of the "Guide for the Care and Use of Laboratory Animals" prepared by Rakuno Gakuen University. The present study was approved by the Animal Care and Use Committee of Rakuno Gakuen University (approval no. VH15B20).

\section{Experiments}

The dogs were used for four experiments with 14- to 28-day washout periods. Food was withheld from the dogs for 12 hr before the experiments. Each dog was instrumented for the experiment under sevoflurane anesthesia. Following this, the dogs received a rocuronium infusion for 120 min during steady-state sevoflurane anesthesia with 1.25-, 1.5-, 1.75-, or 2.0-fold of the predetermined individual sevoflurane MAC administered in random order according to a modified Latin-square design. For each of the MAC multiples, neuromuscular function, cardiorespiratory parameters, and rocuronium plasma concentration (Cp) were monitored before, during, and after rocuronium infusion in dogs anesthetized with sevoflurane. The dogs were classified as recovered from sevoflurane anesthesia when neuromuscular function recovered after the cessation of rocuronium infusion.

\section{Instrumentation, anesthesia, and neuromuscular blockade}

The dogs were orotracheally intubated and anesthetized with sevoflurane (Sevoflo; DS Pharma Animal Health Co., Ltd., Osaka, Japan) vehiculated in 100\% oxygen via a mask. Anesthesia was maintained with 1.25 -fold of the predetermined individual sevoflurane MAC during instrumentation. The dogs were catheterized using a 22-guage catheter (Supercath; Medikit Co., Ltd., Tokyo, Japan) inserted into the right cephalic vein. Throughout anesthesia, the dogs were intravenously administered lactated Ringer's solution (Solulact; Terumo Co., Ltd., Tokyo, Japan) at a rate of $5 \mathrm{ml} / \mathrm{kg} / \mathrm{hr}$ using a precision infusion pump (TOP-2200; TOP Corporation, Tokyo, Japan). Another 22-guage catheter was placed into the left cephalic vein and used for rocuronium infusion. The right dorsal pedal artery was also cannulated with a 22-guage catheter for measuring direct arterial blood pressure and sampling arterial blood. After catheter placement was completed, the dogs were positioned in right lateral recumbency and an acceleromyography (AMG) monitor (TOF-Watch SX; MSD Co., Inc., Tokyo, Japan) was placed on the left hind limb. The left crus was immobilized by fixing it to a pillow while the hind limb articulated freely at the tarsus and was maintained parallel to the table. After hair clipping, surface stimulating electrodes with 10-mm contact areas (Alelode; Sekisui Plastics Co., Ltd., Osaka, Japan) were placed approximately $2.5 \mathrm{~cm}$ apart on the skin surface over the peroneal nerve of the left crus. The negative electrode was placed distally. An AMG monitor acceleration transducer was taped to the dorsal aspect of the left metatarsus.

After completing the instrumentation, the end-tidal concentration of sevoflurane (ETsev) was set at 1.25-, 1.5-, 1.75-, or 2.0-fold of the predetermined individual sevoflurane MAC and an intermittent positive pressure ventilation (IPPV) using a time-cycled ventilator (Nuffield Anesthesia Ventilator Series 200; Penlon, Abingdon, UK) was started to maintain the partial pressure of arterial $\mathrm{CO}_{2}\left(\mathrm{PaCO}_{2}\right)$ between 35-45 mmHg for each dog. Following a 40-min equilibration for each of the sevoflurane MAC multiples, rocuronium bromide (ESLAX Intravenous; MSD Co., Inc.) was intravenously administered at a loading dose of $0.5 \mathrm{mg} /$ $\mathrm{kg}$ for $1 \mathrm{~min}$ and then infused at a maintenance dose of $0.2 \mathrm{mg} / \mathrm{kg} / \mathrm{hr}$ CRI for $120 \mathrm{~min}$ using a precision syringe infusion pump 
(TOP-5300E; TOP Corp.). During the equilibration and rocuronium infusion, esophageal temperature was maintained between $37.5-38.5^{\circ} \mathrm{C}$ using a warm air blanket.

\section{Neuromuscular function monitoring}

Neuromuscular function was evaluated with train-of-four (TOF) stimulation using the AMG monitor (TOF-Watch SX; MSD Co., Inc.) placed on the left hind limb of each dog. A 2-Hz TOF stimulation (four twitches, 0.2-msec pulse duration) was applied to the left peroneal nerve for $2.0 \mathrm{sec}$. After the 40-min equilibration for each sevoflurane MAC multiple, the AMG monitor was calibrated with a calibration function that automatically detected the supramaximal current and set the amplitude of twitch acceleration to $100 \%$. Then, the TOF stimulation was applied to the left peroneal nerve with the supramaximal current. The number of twitches (TOF count) and amplitudes of the first (T1) and fourth (T4) twitches of the TOF were measured, and the TOF ratio (i.e., the T4 amplitude divided by the T1 amplitude) was calculated (baseline TOF ratio).

Following the loading dose of rocuronium, the TOF stimulations were applied at 15 -sec intervals until TOF count 0 was detected. Then, the TOF stimulations were delivered and the TOF counts and ratios were measured at 10, 20, 30, 40, 50, 60, 80, 100, and $120 \mathrm{~min}$ of rocuronium infusion. Time from rocuronium loading dose administration to achieving TOF count 0 (onset time), time from achieving TOF count 0 to the reappearance of TOF count 4 (maximum blockade period), and time from the onset of neuromuscular blockade to attaining a TOF ratio of 70 or $90 \%$ (time to $\mathrm{TOFR}_{70}$ or $\mathrm{TOFR}_{90}$ ) were recorded. The dogs recovered from sevoflurane anesthesia after the TOFR ${ }_{90}$ was achieved and were artificially ventilated until the ETsev decreased to $1.0 \%$.

\section{Cardiorespiratory parameter monitoring}

Cardiorespiratory parameters were recorded before administration of the rocuronium loading dose (baseline) and at 10, 20, 30, $40,50,60,80,100$, and $120 \mathrm{~min}$ of rocuronium infusion. Esophageal temperature $\left({ }^{\circ} \mathrm{C}\right)$, heart rate (beats/min), electrocardiography (monitored through lead II), respiratory rate (breaths/min), mean arterial blood pressure (MAP; mmHg), and ETsev (\%) were measured using a veterinary patient monitoring system (BP-608V; Omron Colin, Ltd., Tokyo, Japan). Arterial blood pressure was directly measured by connecting the catheter placed in the dorsal pedal artery to a pressure transducer (BD DTX Plus DT-4812; Japan Becton, Dickinson and Co., Fukushima, Japan) that was placed and zeroed at the level of the mid-sternum.

An arterial blood sample $(3.0 \mathrm{~m} l)$ was collected into heparinized syringes (30 units per $1 \mathrm{~m} l$ of blood) before the administration of rocuronium and 20,40,60, 80, 100, and $120 \mathrm{~min}$ after the beginning of rocuronium infusion. From the 3-m $l$ arterial sample, $0.5 \mathrm{~m} l$ was immediately analyzed for arterial $\mathrm{pH}(\mathrm{pHa})$, partial pressure of arterial oxygen $\left(\mathrm{PaO}_{2}\right)$, and $\mathrm{PaCO}_{2}$ using a blood gas analyzer (GEM Premier 3000; Instrumentation Laboratory Japan Co., Ltd., Tokyo, Japan).

\section{Analyzing the Cp of rocuronium}

The $\mathrm{Cp}$ of rocuronium was analyzed using a Liquid Chromatography-Mass Spectrometry (LC/MS) system (6120 single quadrupole LC/MS system combined with Agilent 1260 Infinity series; Agilent Technologies Japan, Ltd., Hachioji, Japan). The remainder $(2.5 \mathrm{ml})$ of the arterial blood samples collected from the dogs before and after the beginning of rocuronium infusion as

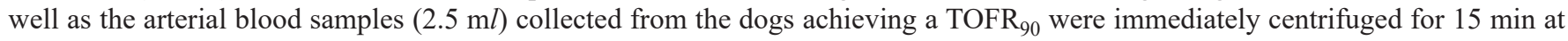
$3,000 \mathrm{rpm}$ to separate the plasma. The plasma samples were acidified with $200 \mu l$ of $1 \mathrm{M}$ sodium dihydrogenphosphate per $\mathrm{m} l$ of plasma and stored at $-80^{\circ} \mathrm{C}$ until analysis.

A $0.2-\mathrm{m} l$ plasma sample was mixed with $1 \mathrm{~m} l$ of methanol and $400 \mu l$ of chloroform and centrifuged at $21,000 \times \mathrm{g}$ for 5 min. The supernatant was mixed with $400 \mu l$ of $\mathrm{H}_{2} \mathrm{O}$ and $200 \mu l$ of chloroform and centrifuged at $21,000 \times \mathrm{g}$ for $2 \mathrm{~min}$. The upper polar phase was dried out using a centrifugal vacuum concentrator (CC-105 with Ulvac DTU-20; TOMY Seiko Co., Ltd., Tokyo, Japan) connected to a cold trap (TU-500; TOMY Seiko Co., Ltd.). The dried pellet was dissolved into $50 \mu l$ of chloroform and washed with $18 \mathrm{mg}$ of graphite powder (FUJIFILM Wako Pure Chemical Corporation, Osaka, Japan). After the dissolved fluid was dried out by the centrifugal vacuum concentrator, the pellet was dissolved into $600 \mu l$ of solution containing acetonitrile:hexane:isobutanol:1-butanol (9:1:0.5:0.5) and added to $400 \mu \mathrm{l}$ of hexane. After centrifugation at 21,000 $\times \mathrm{g}$ for $2 \mathrm{~min}$, the upper hexane phase was removed and dried out by the centrifugal vacuum concentrator. The pellet was dissolved into a $100 \mu l$ solution of $10 \mu l$ of pyridine, $2 \mu l$ of reserpine, $30 \mu l$ of $\mathrm{H}_{2} \mathrm{O}$, and $58 \mu l$ of acetonitrile. A 5- $\mu l$ sample of this dissolved mixture was loaded into the LC/MS system.

Liquid chromatographic separation was achieved with a superficially porous column $(4.6 \times 50 \mathrm{~mm}, 2.7-\mu \mathrm{m}$ particle size; Poroshell 120 EC-C18; Agilent Technologies Japan, Ltd.) maintained at $35^{\circ} \mathrm{C}$ using a gradient mobile phase consisting of $0.1 \%$ formate in $\mathrm{H}_{2} \mathrm{O}$ (A) and $0.1 \%$ formate in acetonitrile (B) delivered at $0.5 \mathrm{ml} / \mathrm{min}$ for $1 \mathrm{~min}$ with $100 \%$ of B, 4 min with $30 \%$ of B and $70 \%$ of A, 8 min with $10 \%$ of B and $90 \%$ of A, and 15 min with $100 \%$ of B. Mass spectrometry was operated in the electronic spray positive ion mode under the optimized condition setting at $12-l /$ min nebulizer gas onflow, $70-\mathrm{V}$ fragmentor voltage, $3,000-\mathrm{V}$ capillary voltage, $350^{\circ} \mathrm{C}$ dry gas, and 195 -sec dwell time. Quantification was performed in the selected-ion monitoring mode selecting $\mathrm{m} / \mathrm{z} 265$ for rocuronium. The $\mathrm{Cp}$ of rocuronium was calculated using a standard curve for rocuronium bromide (SigmaAldrich Japan, Tokyo, Japan) between $5 \mathrm{pM} / \mathrm{m} l$ and $50 \mathrm{nM} / \mathrm{m} l$. Under these conditions, the lower limit of quantification for rocuronium was $5 \mathrm{pM} / \mathrm{ml}$. The area under the curve from the baseline to $120 \mathrm{~min}\left(\mathrm{AUC}_{0-120}\right)$ for rocuronium $\mathrm{Cp}$ was calculated using the linear trapezoidal rule method [42].

\section{Statistical analysis}

All statistical analyses were performed using EZR (Saitama Medical Center; Jichi Medical University, Saitama, Japan), which 


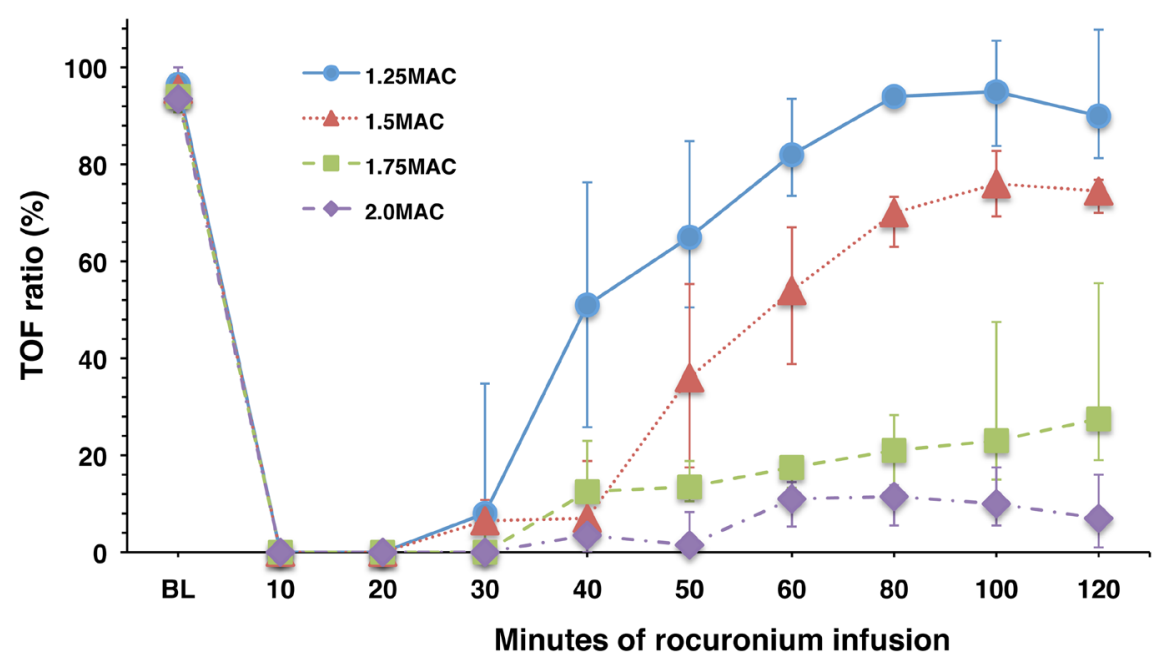

Fig. 1. Changes in the train-of-four (TOF) ratio during rocuronium infusion in sevoflurane-anesthetized dogs. Plots and error bars are expressed as median and interquartile range for 6 dogs. BL: baseline value.

Table 1. The baseline TOF ratio, onset time, blockade period, time to $\mathrm{TOFR}_{70}$ and $\mathrm{TOFR}_{90}, \mathrm{AUC}_{0-120}$, and plasma rocuronium concentration at $\mathrm{TOFR}_{90}$ for each sevoflurane MAC multiple in dogs receiving rocuronium infusion

\begin{tabular}{|c|c|c|c|c|}
\hline & \multicolumn{4}{|c|}{ Sevoflurane MAC multiples } \\
\hline & $1.25 \mathrm{MAC}$ & $1.5 \mathrm{MAC}$ & $1.75 \mathrm{MAC}$ & $2.0 \mathrm{MAC}$ \\
\hline Baseline TOF ratio $(\%)$ & $96 \pm 3$ & $98 \pm 7$ & $95 \pm 5$ & $97 \pm 7$ \\
\hline Onset time (sec) & $108 \pm 20$ & $110 \pm 35$ & $140 \pm 74$ & $112 \pm 36$ \\
\hline Maximum blockade period (min) & $26.0 \pm 4.2$ & $31.7 \pm 9.3$ & $30.8 \pm 5.8$ & $39.2 \pm 12.8$ \\
\hline Time to $\mathrm{TOFR}_{70}(\mathrm{~min})$ & $55.0(38.8-60.0)$ & $97.5(80.0-115.0)$ & $122.0(121.6-123.8)^{\mathrm{a})}$ & $126.0(124.6-128.1)^{\mathrm{a}, \mathrm{b})}$ \\
\hline Time to $\operatorname{TOFR}_{90}(\mathrm{~min})$ & $77.5(56.3-80.0)$ & $121.3(121.1-121.4)$ & $122.6(122.3-124.9)^{\mathrm{a})}$ & $\left.131.4(128.4-132.4)^{\mathrm{a}, \mathrm{b}}\right)$ \\
\hline $\operatorname{AUC}_{0-120}(n \mathrm{~g} / \mathrm{m} l / \mathrm{min})$ & $298 \pm 74$ & $426 \pm 137$ & $385 \pm 111$ & $318 \pm 94$ \\
\hline Plasma rocuronium concentration at $\operatorname{TOFR}_{90}(n \mathrm{~g} / \mathrm{m} l)$ & $312 \pm 142$ & $193 \pm 107$ & $137 \pm 49$ & $123 \pm 82^{\mathrm{a})}$ \\
\hline
\end{tabular}

Parametric values are presented as mean \pm standard deviation and non-parametric values are presented as median (interquartile range). TOF: train-of-four, Onset time: time from rocuronium loading dose administration to achieving TOF count 0 , Maximum blockade period: time from achieving TOF count 0 to TOF count 4 reappearance, $\mathrm{TOFR}_{70}$ and $\mathrm{TOFR}_{90}$ : TOF ratios of 70 and $90 \%$, Time to $\mathrm{TOFR}_{70}$ : time from the onset of neuromuscular blockade to attaining TOFR ${ }_{70}$, Time to TOFR 90 : time from the onset of neuromuscular blockade to attaining TOFR ${ }_{90}, \mathrm{AUC}_{0-120}$ : area under the curve from the baseline to 120 min of plasma rocuronium concentration. a) Significantly different from 1.25 MAC $(P<0.05)$. b) Significantly different from 1.5 MAC $(P<0.05)$.

is a graphical user interface for R (The R Foundation for Statistical Computing, Vienna, Austria). All data were analyzed normally using the Kolmogorov-Smirnov test. Parametric values are presented as mean \pm standard deviation (SD) and non-parametric values are presented as median (interquartile range). The baseline value of the TOF ratio, onset time, blockade period, $\mathrm{AUC}_{0-120}$, and rocuronium $\mathrm{Cp}$ at $\mathrm{TOFR}_{90}$ were compared by one-way ANOVA with Tukey-Kramer post hoc test. The times to TOFR 70 and TOFR $_{90}$ were compared between the sevoflurane MAC multiples using Kruskal-Wallis and Steel-Dwass post hoc tests. Changes in cardiorespiratory parameters, except for the $\mathrm{pHa}$ and $\mathrm{PaCO}_{2}$, were compared between the sevoflurane MAC multiples using twoway repeated-measure ANOVA followed by Tukey-Kramer post hoc test. Changes in the $\mathrm{pHa}$ and $\mathrm{PaCO}_{2}$ were compared between the sevoflurane MAC multiples using the Friedman test with Bonferroni post hoc test. All cardiorespiratory parameters were compared to their baselines with one-way ANOVA followed by Dunnett post hoc test. The level of significance was set at $P<0.05$.

\section{RESULTS}

The sevoflurane MAC ranged from 1.92 to $2.57 \%$ and its mean \pm SD was $2.10 \pm 0.24 \%$. Based on the sevoflurane MACs, the ETsev delivered to each dog ranged between 2.40-3.21\% for 1.25 sevoflurane MAC, 2.88-3.86\% for 1.5 sevoflurane MAC, $3.36-4.50 \%$ for 1.75 sevoflurane MAC, and 3.84-5.14\% for 2.0 sevoflurane MAC. Following the completion of each experiment, all dogs recovered from sevoflurane anesthesia and neuromuscular blockade without any adverse effects.

Figure 1 shows the time-dependent changes in the TOF ratio during rocuronium infusion. The baseline TOF ratio, onset time, blockade period, and times to $\mathrm{TOFR}_{70}$ and $\mathrm{TOFR}_{90}$ for each sevoflurane MAC multiple are summarized in Table 1 . In one dog anesthetized with 1.25 sevoflurane MAC, TOF count 0 was not achieved; however, an apparent muscular blockade (TOF count 4) had been detected for 20 min following rocuronium loading dose administration. Therefore, this dog was excluded from statistical analyses concerning the onset time and blockade period. Maximum neuromuscular blockade (TOF count 0 ) was achieved within 2 


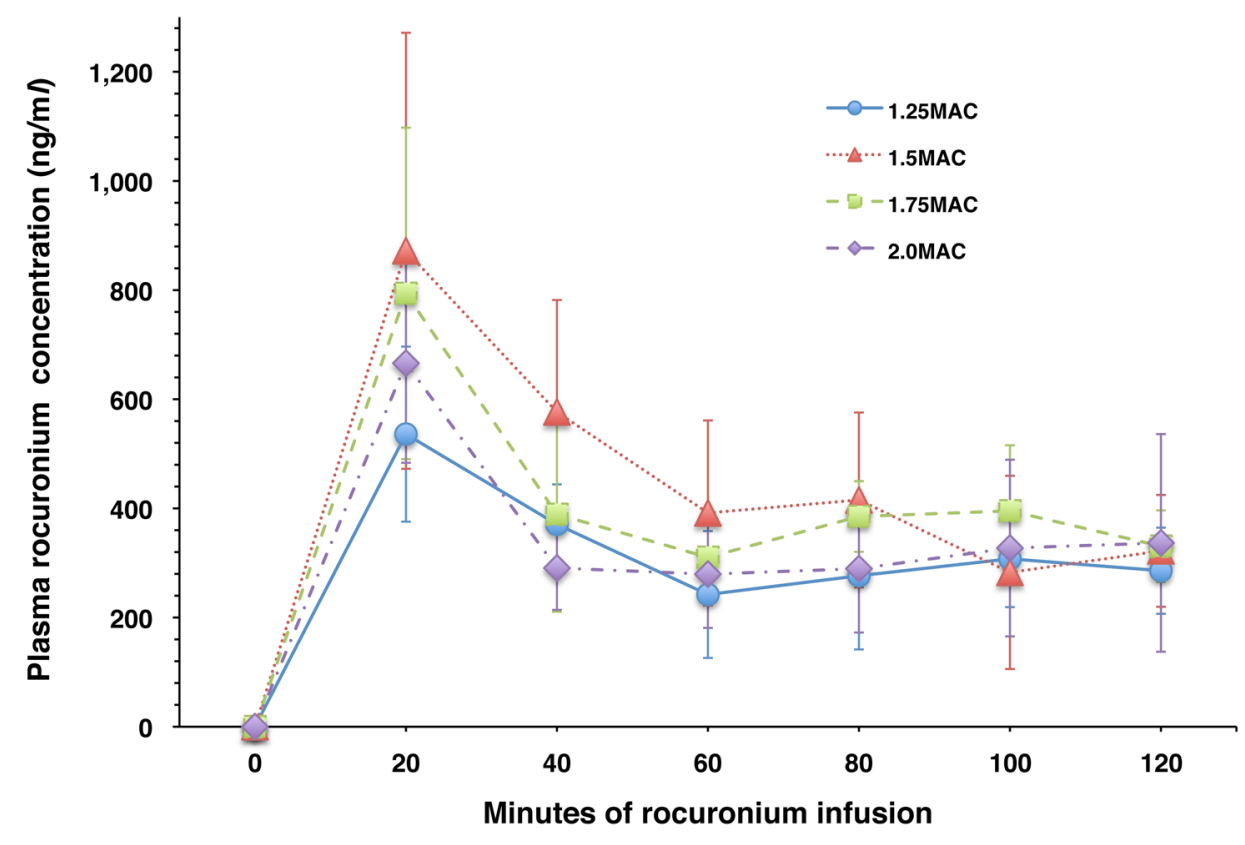

Fig. 2. Changes in plasma rocuronium concentration during rocuronium infusion in sevoflurane-anesthetized dogs. Plots and error bars are expressed as median and interquartile range for 6 dogs.

min after administration of the rocuronium loading dose in almost all of the dogs, and the mean maximum blockade period ranged from 26.0 to $39.2 \mathrm{~min}$. There were no significant differences between the sevoflurane MAC multiples for the baselines of the TOF ratio, onset time, and maximum blockade period.

Muscular twitches reappeared at 30 and $50 \mathrm{~min}$ of rocuronium infusion in all dogs anesthetized with 1.25 and $1.5 \mathrm{MAC}$ of sevoflurane, respectively. At 60 min of rocuronium infusion, the TOF ratio recovered to over $70 \%$ in all dogs anesthetized with 1.25 MAC of sevoflurane. In contrast, the times to TOFR 70 and TOFR 90 were significantly prolonged in dogs anesthetized with 1.75 MAC of sevoflurane compared to dogs anesthetized with 1.25 MAC of sevoflurane $(P=0.020$ and $P=0.020$, respectively). The times to $\mathrm{TOFR}_{70}$ and TOFR 90 were significantly prolonged in dogs anesthetized with $2.0 \mathrm{MAC}$ of sevoflurane compared to dogs anesthetized with 1.25 MAC of sevoflurane $(P=0.020$ and $P=0.020$, respectively) and 1.5 MAC of sevoflurane ( $P=0.033$ and $P=0.032$, respectively).

Figure 2 shows the time-concentration profiles of rocuronium $\mathrm{Cp}$ in dogs anesthetized with each sevoflurane MAC multiple. The $\mathrm{AUC}_{0-120}$ and rocuronium $\mathrm{Cp}$ measured at $\mathrm{TOFR}_{90}$ are summarized in Table 1. There was no significant difference in the time-dependent changes in rocuronium $\mathrm{Cp}$ between the sevoflurane MAC multiples. The mean rocuronium $\mathrm{Cp}$ ranged from 536 to $872 \mathrm{ng} / \mathrm{ml}$ at $20 \mathrm{~min}$ of rocuronium infusion. Between 60-120 min of rocuronium infusion, the rocuronium Cp decreased rapidly and ranged from 242 to $396 \mathrm{ng} / \mathrm{ml}$. There was no significant difference in the $\mathrm{AUC}_{0-120}$ between the sevoflurane MAC multiples $(P=0.877)$. The rocuronium $\mathrm{Cp}$ at $\mathrm{TOFR}_{90}$ of dogs anesthetized with 2.0 sevoflurane MAC was significantly lower than that of dogs anesthetized with 1.25 sevoflurane $\operatorname{MAC}(P=0.046)$.

Changes in the cardiorespiratory parameters are summarized in Table 2. There was no significant difference in all cardiorespiratory parameters compared to their baseline values. There was no significant difference in $\mathrm{MAP}_{\text {and }} \mathrm{PaO} \mathrm{O}_{2}$ between the sevoflurane MAC multiples. The heart rates of dogs anesthetized with 1.25 sevoflurane MAC were lower than those of dogs anesthetized with $1.5,1.75$, or $2.0 \mathrm{MAC}$ of sevoflurane $(P=0.002, P<0.001$, and $P<0.001$, respectively). Clinically relevant hypotension (MAP $<60 \mathrm{mmHg}$ ) was produced in 4 and 5 dogs anesthetized with 1.75 and 2.0 MAC of sevoflurane, respectively. Normal acid-base balance and normocapnia were preserved in all of the dogs throughout the experiments; however, statistical differences were detected in the pHa between dogs anesthetized with 1.25 and 1.75 or 2.0 MAC of sevoflurane $(P=0.049$ or $P=0.006$, respectively) and $\mathrm{PaCO}_{2}$ between dogs anesthetized with 1.25 and $2.0 \mathrm{MAC}(P=0.049)$.

\section{DISCUSSION}

In the present study, sevoflurane anesthesia produced dose-dependent prolongation of recovery from neuromuscular blockade produced by rocuronium infusion in dogs. However, there was no significant difference between the sevoflurane MAC multiples for the time-concentration profiles of rocuronium $\mathrm{Cp}$. It was inferred that, in dogs, sevoflurane potentiated the neuromuscular blockade of rocuronium through its effect on rocuronium pharmacodynamics at the neuromuscular junction rather than rocuronium pharmacokinetics. As we hypothesized, sevoflurane anesthesia potentiated the neuromuscular blockade produced by rocuronium, particularly its recovery phase, in a dose-dependent manner. In the present study, the times to TOFR 70 and TOFR 90 were 
Table 2. Changes in cardiorespiratory parameters during rocuronium infusion in dogs anesthetized with each sevoflurane multiple

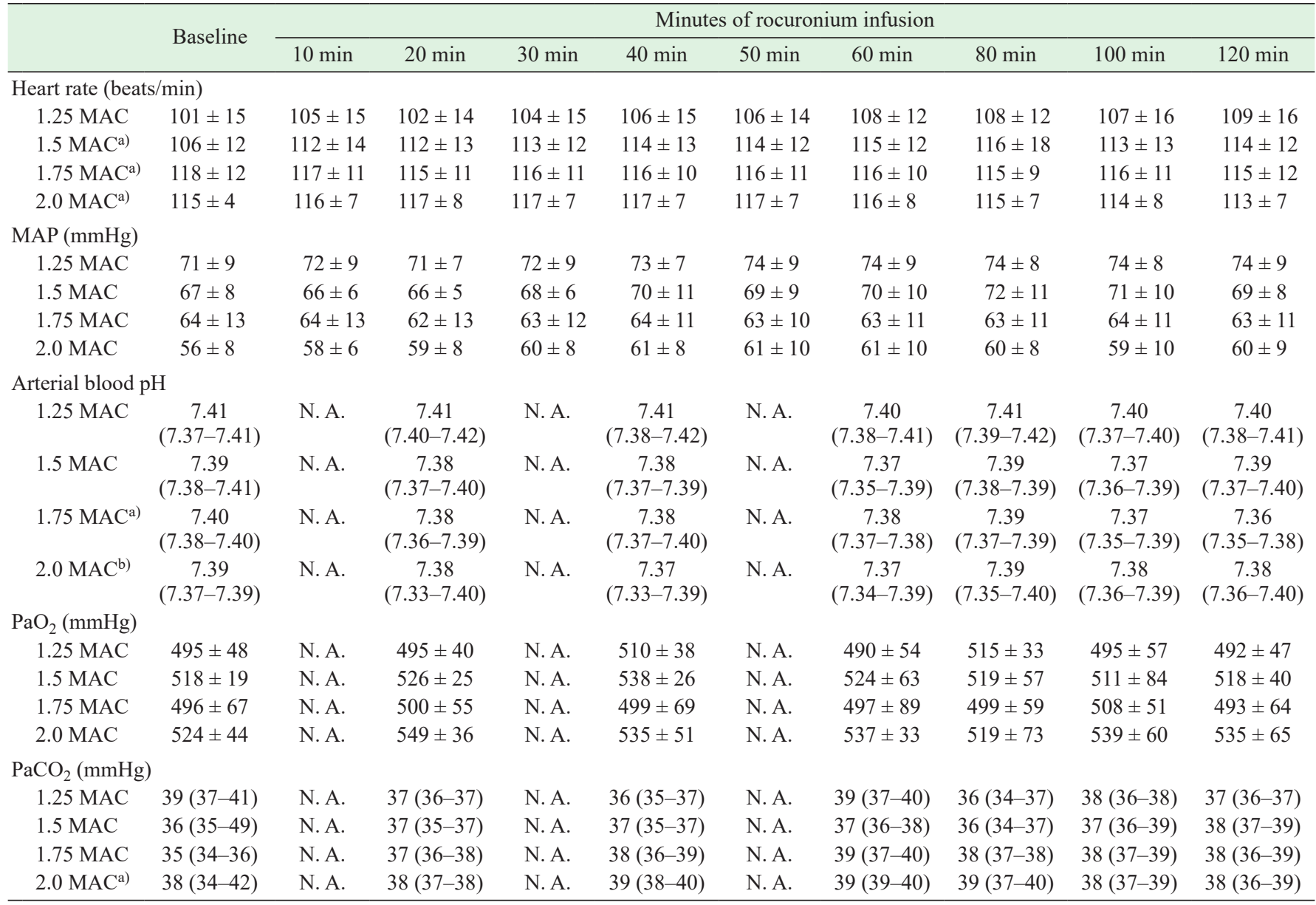

Parametric values are presented as mean \pm standard deviation and non-parametric values are presented as median (interquartile range). MAP: mean arterial blood pressure, $\mathrm{PaO}_{2}$ : partial pressure of arterial oxygen, $\mathrm{PaCO}_{2}$ : partial pressure of arterial carbon dioxide, N.A.: not applicable. Significantly different from 1.25 MAC: a) $P<0.05$, b) $P<0.01$.

recorded to evaluate the duration of neuromuscular blockade produced by rocuronium infusion according to previous research recommendations [18] and a canine clinical study [1]. The TOF ratio recovered to over $70 \%$ in dogs anesthetized with 1.25 and 1.5 MAC of sevoflurane by $120 \mathrm{~min}$ of rocuronium infusion. Moreover, the TOF ratio recovered to over $90 \%$ in dogs anesthetized with 1.25 MAC of sevoflurane by 120 min of rocuronium infusion. However, the time to TOFR 70 was longer than 120 min in dogs

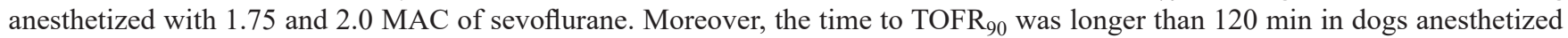

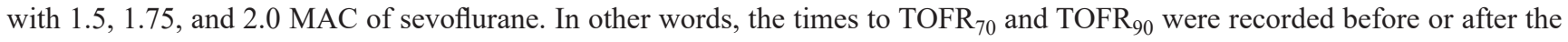
cessation of the 120-min rocuronium infusion. We suggest that, in dogs anesthetized with over 1.5 MAC of sevoflurane, the times to $\mathrm{TOFR}_{70}$ and $\mathrm{TOFR}_{90}$ would be longer for rocuronium infusion lasting longer than $120 \mathrm{~min}$.

In the present study, the protocol for rocuronium administration was based on a previous report that investigated rocuronium infusion in 22 dogs anesthetized with isoflurane in nitrous oxide and oxygen for various elective surgical procedures [1]. An IV rocuronium loading dose of $0.5 \mathrm{mg} / \mathrm{kg}$ produced a rapid and complete neuromuscular blockade in dogs for each sevoflurane MAC multiple. The onset time of complete neuromuscular blockade (TOF count 0 ) for each sevoflurane MAC multiple was similar to that found by previous studies of dogs administered an IV rocuronium loading dose of $0.5 \mathrm{mg} / \mathrm{kg}$ (median: $82 \mathrm{sec}$, range: $38-184$ $\mathrm{sec}$ ) [1] and a single IV bolus dose of rocuronium at $0.4 \mathrm{mg} / \mathrm{kg}$ (mean $\pm \mathrm{SD}: 98 \pm 52 \mathrm{sec}$ ) [13]. In the present study, there was no significant difference in the onset time between the sevoflurane MAC multiples. We suggest that a complete neuromuscular blockade was rapidly achieved by the IV rocuronium loading dose. Moreover, the neuromuscular blockade was not affected by the depth of sevoflurane anesthesia in most of the dogs.

In the present study, one dog anesthetized with 1.25 MAC of sevoflurane failed to achieve TOF count 0 , although an apparent muscular blockade (TOF count 4) was detected following administration of the rocuronium loading dose. Alderson et al. [1] also reported that TOF count 0 was not achieved in one of the 22 dogs examined following administration of the IV rocuronium loading dose $(0.5 \mathrm{mg} / \mathrm{kg})$. Moreover, these authors reported that three other dogs had muscular twitches following TOF stimulation and spontaneous respiration return before the end of rocuronium infusion $(0.2 \mathrm{mg} / \mathrm{kg} / \mathrm{hr})$. It is strongly suggested that rocuronium produces neuromuscular blockade with inter-individual variation in dogs [1]. Alternatively, a muscle may contract in response to 
direct muscle stimulation as opposed to indirect nerve stimulation. Such direct muscle stimulation is characterized by persistent twitching or a TOF response without fade during intense blockade [18]. In this individual, we suggest that the incomplete neuromuscular blockade was produced by insufficient rocuronium dosage or direct muscle stimulation.

Ezzine et al. [16] reported that a complete neuromuscular blockade was achieved by rocuronium infusion $(0.15 \mathrm{mg} / \mathrm{kg} / \mathrm{min} \mathrm{CRI}$ for $2 \mathrm{~min}$ followed by $3.6 \mathrm{mg} / \mathrm{kg} / \mathrm{hr}$ CRI for $118 \mathrm{~min}$ ) in dogs anesthetized with sodium pentobarbital. Moreover, these authors reported that the effective plasma concentration at $50 \%$ neuromuscular blockade $\left(\mathrm{EC}_{50}\right) \mathrm{was} 353 \mathrm{ng} / \mathrm{ml}$. In the present study, the maximum neuromuscular blockade period ranged from 26.0 to $39.2 \mathrm{~min}$, and the mean rocuronium $\mathrm{Cp}$ at $20 \mathrm{~min}$ of rocuronium infusion (536-872 $\mathrm{ng} / \mathrm{m} l$ ) was more than the $\mathrm{EC}_{50}$ of anesthetized $\operatorname{dogs}$ [16]. Moreover, the mean rocuronium $\mathrm{Cp}$ at 60-120 min of rocuronium infusion $(242-396 \mathrm{ng} / \mathrm{m} l)$ was similar to the $\mathrm{EC}_{50}$ [16], and the TOF ratio recovered to over $70 \%$ in all dogs anesthetized with 1.25 MAC of sevoflurane at $60 \mathrm{~min}$ of rocuronium infusion. In contrast, the recovery from neuromuscular blockade was significantly prolonged in dogs anesthetized with 1.75 and 2.0 MAC of sevoflurane; however, the mean rocuronium $\mathrm{Cp}$ at 60-120 min of rocuronium infusion was similar to the $\mathrm{EC}_{50}$ [16]. Furthermore, the rocuronium $\mathrm{Cp}$ when the neuromuscular blockade recovered to the TOFR $_{90}$ was significantly lower in dogs anesthetized with 2.0 MAC of sevoflurane compared to that in dogs anesthetized with 1.25 MAC of sevoflurane. A dose-dependent potentiation of the neuromuscular blockade by sevoflurane anesthesia has appeared after the cessation of rocuronium infusion. Paul et al. [41] reported that sevoflurane caused a dosedependent inhibition of adult mouse muscle nAChRs by potentially enhancing antagonist affinity at the receptor site. Moreover, these authors found that sevoflurane enhanced neuromuscular blockade produced by vecuronium and d-tubocurarine. Liu et al. [27] also reported that the inhibitory effect of rocuronium on the inward current of the adult mouse nAChR was enhanced by sevoflurane in a concentration-dependent manner. These in vitro studies showed that the co-application of sevoflurane significantly enhanced the inhibitory effects of NDMBAs [27, 41]. Moreover, these studies demonstrated that a lower NDMBA concentration resulted in a stronger synergistic effect with sevoflurane [27, 41]. It has been suggested that sevoflurane might potentiate the neuromuscular blockade of rocuronium by strengthening rocuronium pharmacodynamics at the neuromuscular junction, particularly at a lower rocuronium Cp. For isoflurane-anesthetized dogs, Sakai et al. [43] reported that neuromuscular function recovered more slowly in the larynx compared to the pelvic limb after IV administration of rocuronium $(0.6 \mathrm{mg} / \mathrm{kg})$. Moreover, in anesthetized dogs receiving atracurium infusion, Tseng et al. [47] reported that tidal volume reduction at peak inspiration in response to hypercapnic challenge was accompanied by decreased abduction of the arytenoid cartilages. This dysfunction was even present at shallow levels (TOF ratios between 70-90\%) of neuromuscular blockade [47]. Therefore, veterinary practitioners should be aware of residual neuromuscular blockade and respiratory dysfunction produced by the synergistic effect of low rocuronium $\mathrm{Cp}$ with sevoflurane anesthesia in dogs.

The most important factors that may influence the effect of NDMBAs are age, physical status, sex, body weight, anesthetic technique, monitoring method [18], body temperature [19], and acid-base differences [26, 39, 40]. For the present study, we suggest that the age, physical status, and body weight of the dogs minimally impacted the effect of the neuromuscular blockade produced by rocuronium infusion since their backgrounds were the same. Moreover, the esophageal temperature was maintained between $37.5-38.5^{\circ} \mathrm{C}$, and normal acid-base balance and normocapnia were achieved throughout the experiments. To avoid sex bias in our data, we used the same number of female and male dogs to offset sex differences. Consequently, the differences between the sevoflurane MAC multiples with respect to the profiles of the neuromuscular blockade produced by rocuronium infusion must be produced by different sevoflurane doses.

The muscular response to nerve stimulation depends on the frequency of the individual stimuli applied [18]. Stimulus patterns have been shown to produce different pharmacodynamic data $[2,9,10,14,18,28,34]$. Moreover, the time elapsed to achieve a stable control response may influence the subsequent determination of onset time and blockade duration [18, 33]. In general, increased stimulus frequency will shorten the onset time of NDMBAs and prolong their duration of action [18]. The duration of the impulses should not exceed $0.3 \mathrm{msec}$ to avoid repetitive firing and decrease the likelihood of direct muscle stimulation [24, 38]. Moreover, a stimulus duration of $0.2 \mathrm{msec}$ is recommended [18]. In accordance with these recommendations [18, 24, 38] and previous canine studies $[1,22,36,37,44]$, a $2-\mathrm{Hz}$ TOF stimulation with a $0.2-\mathrm{msec}$ pulse duration was applied to the left peroneal nerve in the present study.

When a nerve is stimulated with sufficient intensity, all of the muscle fibers supplied by the nerve will contract, and the maximum response will be triggered. The stimulus must be maximal throughout the monitoring period to ensure that a decreased response after NDMBA injection is caused by the drug and not by a decrease in fiber activation due to submaximal stimulation or an increase in skin impedance [18]. In accordance with previous research recommendations [18] and a previous canine study [29], the AMG monitor (TOF-Watch SX) in the present study was calibrated to automatically detect the supramaximal current and set the twitch acceleration amplitude to $100 \%$ before rocuronium infusion. Therefore, a supramaximal electrical stimulus must be applied to achieve a maximal response during rocuronium infusion.

Mechanomyography (MMG) is considered to be the gold standard for neuromuscular monitoring during anesthesia [8, 18]. However, MMG involves cumbersome setups (e.g., connection of a muscle or tendon to a wire or suture and a force transducer) and can be impractical for routine use in the operating room. AMG was introduced to clinical practice as an alternative to MMG $[21,48]$. In humans, initial comparisons of AMG with MMG demonstrated a close linear relationship between these monitors; however, AMG values were mildly overestimated [48]. Due to its simplicity and affordability, AMG has gained acceptance in clinical settings and is commonly used as an objective method for monitoring neuromuscular transmission in human and veterinary anesthesia. Moreover, AMG has been increasingly used as a research tool in dogs to quantify neuromuscular function [1, 22, 36, 37]. Recently, Sakai et al. [44] compared measurements of neuromuscular function with MMG and AMG in nine anesthetized dogs 
receiving vecuronium and concluded that individual differences may preclude the interchangeable use of MMG and AMG data. However, AMG is still a useful tool since its benefits for detecting residual neuromuscular block have been well established in dogs $[31,44]$. As in previous canine studies [22, 31, 36, 37, 40, 44], AMG was used in the present study for the quantification of neuromuscular function. However, unlike these studies, the hind limb equipped with the AMG monitor was freely articulated at the tarsus. Originally, unrestricted limb movement was considered a prerequisite for the use of AMG [48]; however, there is increasing evidence that a small elastic preload on the limb in the range of 75-150 g may decrease variability [12, 24]. The differences in the degree of neuromuscular blockade between the sevoflurane MAC multiples might have been more evident had a small elastic preload been applied to the limb equipped with the AMG monitor.

In human medicine, simultaneously recording the height of the first twitch (T1 value) during TOF stimulation is recommended [18]. However, in anesthetized dogs, the T1 value could be increased by repeated TOF stimulation during the course of recovery from neuromuscular blockade with an NDMBA [30]. This staircase phenomenon may introduce bias to T1 value measurements. However, in anesthetized dogs, the influence of the staircase phenomenon is minimal for the TOF ratio [30, 32]. Therefore, in the present study, the degree of neuromuscular blockade was evaluated using the TOF ratio.

Sevoflurane anesthesia causes dose-dependent circulatory depression that may reduce portal venous blood flow and oxygen supply to the liver in dogs [17]. It is possible that sevoflurane anesthesia may affect the rocuronium Cp because rocuronium is mainly metabolized via the hepatic route [23]. However, portal artery blood flow may increase to maintain the oxygen supply to hepatic parenchymal cells as a result of physiological mechanisms compensating for reduced portal blood flow [4, 15]. In the present study, there was no significant difference in the $\mathrm{AUC}_{0-120}, \mathrm{MAP}$, and $\mathrm{PaO}_{2}$ between the sevoflurane $\mathrm{MAC}$ multiples; however, clinically relevant hypotension was observed in dogs anesthetized with 1.75 and 2.0 MAC of sevoflurane. We speculate that the influence of sevoflurane anesthesia on rocuronium metabolism in the canine liver might be similar in extent between sevoflurane MAC multiples.

In conclusion, sevoflurane anesthesia potentiated the neuromuscular blockade produced by rocuronium in a dose-dependent manner in dogs. Veterinary practitioners should be aware of residual neuromuscular blockade produced by the synergistic effect of low rocuronium $\mathrm{Cp}$ with sevoflurane anesthesia in dogs. Further studies are necessary to confirm whether there are sex differences with respect to the effect of sevoflurane on the neuromuscular blockade produced by rocuronium infusion in dogs.

\section{REFERENCES}

1. Alderson, B., Senior, J. M., Jones, R. S. and Dugdale, A. H. 2007. Use of rocuronium administered by continuous infusion in dogs. Vet. Anaesth. Analg. 34: 251-256. [Medline] [CrossRef]

2. Ali, H. H. and Savarese, J. J. 1980. Stimulus frequency and dose-respone curve to d-tubocurarine in man. Anesthesiology 52: 36-39. [Medline] [CrossRef]

3. Appiah-Ankam, J. and Hunter, J. M. 2004. Pharmacology of neuromuscular blocking drugs. Contin. Educ. Anaesth. Crit. Care Pain 4: 2-7. [CrossRef]

4. Bernard, J. M., Doursout, M. F., Wouters, P., Hartley, C. J., Merin, R. G. and Chelly, J. E. 1992. Effects of sevoflurane and isoflurane on hepatic circulation in the chronically instrumented dog. Anesthesiology 77: 541-545. [Medline] [CrossRef]

5. Bock, M., Klippel, K., Nitsche, B., Bach, A., Martin, E. and Motsch, J. 2000. Rocuronium potency and recovery characteristics during steady-state desflurane, sevoflurane, isoflurane or propofol anaesthesia. Br. J. Anaesth. 84: 43-47. [Medline] [CrossRef]

6. Briganti, A., Barsotti, G., Portela, D. A., Di Nieri, C. and Breghi, G. 2015. Effects of rocuronium bromide on globe position and respiratory function in isoflurane-anesthetized dogs: a comparison between three different dosages. Vet. Ophthalmol. 18: 89-94. [Medline] [CrossRef]

7. Cason, B., Baker, D. G., Hickey, R. F., Miller, R. D. and Agoston, S. 1990. Cardiovascular and neuromuscular effects of three steroidal neuromuscular blocking drugs in dogs (ORG 9616, ORG 9426, ORG 9991). Anesth. Analg. 70: 382-388. [Medline] [CrossRef]

8. Claudius, C. and Viby-Mogensen, J. 2008. Acceleromyography for use in scientific and clinical practice: a systematic review of the evidence. Anesthesiology 108: 1117-1140. [Medline] [CrossRef]

9. Cooper, R. A., Mirakhur, R. K., Elliott, P. and McCarthy, G. J. 1992. Estimation of the potency of ORG 9426 using two different modes of nerve stimulation. Can. J. Anaesth. 39: 139-142. [Medline] [CrossRef]

10. Curran, M. J., Donati, F. and Bevan, D. R. 1987. Onset and recovery of atracurium and suxamethonium-induced neuromuscular blockade with simultaneous train-of-four and single twitch stimulation. Br. J. Anaesth. 59: 989-994. [Medline] [CrossRef]

11. Dragne, A., Varin, F., Plaud, B. and Donati, F. 2002. Rocuronium pharmacokinetic-pharmacodynamic relationship under stable propofol or isoflurane anesthesia. Can. J. Anaesth. 49: 353-360. [Medline] [CrossRef]

12. Dubois, P. E., Gourdin, M., Russell, K. and Jamart, J. 2005. Installation of the hand influences acceleromyography measurement. A comparison with mechanomyography during neuromuscular recovery. Acta Anaesthesiol. Belg. 56: 163-166. [Medline]

13. Dugdale, A. H., Adams, W. A. and Jones, R. S. 2002. The clinical use of the neuromuscular blocking agent rocuronium in dogs. Vet. Anaesth. Analg. 29: 49-53. [Medline] [CrossRef]

14. Eikermann, M. and Peters, J. 2000. Nerve stimulation at $0.15 \mathrm{~Hz}$ when compared to $0.1 \mathrm{~Hz}$ speeds the onset of action of cisatracurium and rocuronium. Acta Anaesthesiol. Scand. 44: 170-174. [Medline] [CrossRef]

15. Eipel, C., Abshagen, K. and Vollmar, B. 2010. Regulation of hepatic blood flow: the hepatic arterial buffer response revisited. World J. Gastroenterol. 16: 6046-6057. [Medline] [CrossRef]

16. Ezzine, S. and Varin, F. 2005. Interstitial muscle concentrations of rocuronium under steady-state conditions in anaesthetized dogs: actual versus predicted values. Br. J. Anaesth. 94: 49-56. [Medline] [CrossRef]

17. Frink, E. J. Jr., Morgan, S. E., Coetzee, A., Conzen, P. F. and Brown, B. R. Jr. 1992. The effects of sevoflurane, halothane, enflurane, and isoflurane on hepatic blood flow and oxygenation in chronically instrumented greyhound dogs. Anesthesiology 76: 85-90. [Medline] [CrossRef]

18. Fuchs-Buder, T., Claudius, C., Skovgaard, L. T., Eriksson, L. I., Mirakhur, R. K., Viby-Mogensen J., 8th International Neuromuscular Meeting. 2007. Good clinical research practice in pharmacodynamic studies of neuromuscular blocking agents II: the Stockholm revision. Acta Anaesthesiol. 
Scand. 51: 789-808. [Medline] [CrossRef]

19. Heier, T. and Caldwell, J. E. 2006. Impact of hypothermia on the response to neuromuscular blocking drugs. Anesthesiology 104: 1070-1080. [Medline] [CrossRef]

20. Jellish, W. S., Brody, M., Sawicki, K. and Slogoff, S. 2000. Recovery from neuromuscular blockade after either bolus and prolonged infusions of cisatracurium or rocuronium using either isoflurane or propofol-based anesthetics. Anesth. Analg. 91: 1250-1255. [Medline]

21. Jensen, E., Viby-Mogensen, J. and Bang, U. 1988. The Accelograph: a new neuromuscular transmission monitor. Acta Anaesthesiol. Scand. 32: 49-52. [Medline] [CrossRef]

22. Kastrup, M. R., Marsico, F. F., Ascoli, F. O., Becker, T., Soares, J. H. and Gomez de Segura, I. A. 2005. Neuromuscular blocking properties of atracurium during sevoflurane or propofol anaesthesia in dogs. Vet. Anaesth. Analg. 32: 222-227. [Medline] [CrossRef]

23. Khuenl-Brady, K., Castagnoli, K. P., Canfell, P. C., Caldwell, J. E., Agoston, S. and Miller, R. D. 1990. The neuromuscular blocking effects and pharmacokinetics of ORG 9426 and ORG 9616 in the cat. Anesthesiology 72: 669-674. [Medline] [CrossRef]

24. Kopman, A. F., Chin, W. and Cyriac, J. 2005. Acceleromyography vs. electromyography: an ipsilateral comparison of the indirectly evoked neuromuscular response to train-of-four stimulation. Acta Anaesthesiol. Scand. 49: 316-322. [Medline] [CrossRef]

25. Kurahashi, K. and Maruta, H. 1996. The effect of sevoflurane and isoflurane on the neuromuscular block produced by vecuronium continuous infusion. Anesth. Analg. 82: 942-947. [Medline]

26. Kuwahara, M. 2004. Respiratory acidosis increases the blocking effect of vecuronium bromide. J. St. Marianna Univ. 31: 1-8.

27. Liu, L., Li, W., Wei, K., Cao, J., Luo, J., Wang, B. and Min, S. 2013. Synergistic effect of sevoflurane and isoflurane on inhibition of the adult-type muscle nicotinic acetylcholine receptor by rocuronium. J. Anesth. 27: 351-358. [Medline] [CrossRef]

28. Maddineni, V. R., Mirakhur, R. K., Cooper, R. and McCoy, E. 1993. Potency estimation of mivacurium: comparison of two different modes of nerve stimulation. Br. J. Anaesth. 70: 694-695. [Medline] [CrossRef]

29. Martin-Flores, M., Gleed, R. D., Basher, K. L., Scarlett, J. M., Campoy, L. and Kopman, A. F. 2012. TOF-Watch(R) monitor: failure to calculate the train-of-four ratio in the absence of baseline calibration in anaesthetized dogs. Br. J. Anaesth. 108: 240-244. [Medline] [CrossRef]

30. Martin-Flores, M., Lau, E. J., Campoy, L., Erb, H. N. and Gleed, R. D. 2011. Twitch potentiation: a potential source of error during neuromuscular monitoring with acceleromyography in anesthetized dogs. Vet. Anaesth. Analg. 38: 328-335. [Medline] [CrossRef]

31. Martin-Flores, M., Sakai, D. M., Campoy, L. and Gleed, R. D. 2014. Recovery from neuromuscular block in dogs: restoration of spontaneous ventilation does not exclude residual blockade. Vet. Anaesth. Analg. 41: 269-277. [Medline] [CrossRef]

32. Martin-Flores, M., Tseng, C. T., Sakai, D. M., Romano, M., Campoy, L. and Gleed, R. D. 2017. Positive and negative staircase effect during single twitch and train-of-four stimulation: a laboratory study in dogs. J. Clin. Monit. Comput. 31: 337-342. [Medline] [CrossRef]

33. McCoy, E. P., Mirakhur, R. K., Connolly, F. M. and Loan, P. B. 1995. The influence of the duration of control stimulation on the onset and recovery of neuromuscular block. Anesth. Analg. 80: 364-367. [Medline]

34. Meretoja, O. A., Taivainen, T., Brandom, B. W. and Wirtavuori, K. 1994. Frequency of train-of-four stimulation influences neuromuscular response. Br. J. Anaesth. 72: 686-687. [Medline] [CrossRef]

35. Miller, D. R., Wherrett, C., Hull, K., Watson, J. and Legault, S. 2000. Cumulation characteristics of cisatracurium and rocuronium during continuous infusion. Can. J. Anaesth. 47: 943-949. [Medline] [CrossRef]

36. Mosing, M., Auer, U., West, E., Jones, R. S. and Hunter, J. M. 2012. Reversal of profound rocuronium or vecuronium-induced neuromuscular block with sugammadex in isoflurane-anaesthetised dogs. Vet. J. 192: 467-471. [Medline] [CrossRef]

37. Nagahama, S., Nishimura, R., Mochizuki, M. and Sasaki, N. 2006. The effects of propofol, isoflurane and sevoflurane on vecuronium infusion rates for surgical muscle relaxation in dogs. Vet. Anaesth. Analg. 33: 169-174. [Medline] [CrossRef]

38. Nepveu, M. E., Donati, F. and Fortier, L. P. 2005. Train-of-four stimulation for adductor pollicis neuromuscular monitoring can be applied at the wrist or over the hand. Anesth. Analg. 100: 149-154. [Medline] [CrossRef]

39. Ono, K., Nagano, O., Ohta, Y. and Kosaka, F. 1990. Neuromuscular effects of respiratory and metabolic acid-base changes in vitro with and without nondepolarizing muscle relaxants. Anesthesiology 73: 710-716. [Medline] [CrossRef]

40. Ono, K., Ohta, Y., Morita, K. and Kosaka, F. 1988. The influence of respiratory-induced acid-base changes on the action of non-depolarizing muscle relaxants in rats. Anesthesiology 68: 357-362. [Medline] [CrossRef]

41. Paul, M., Fokt, R. M., Kindler, C. H., Dipp, N. C. and Yost, C. S. 2002. Characterization of the interactions between volatile anesthetics and neuromuscular blockers at the muscle nicotinic acetylcholine receptor. Anesth. Analg. 95: 362-367. [Medline]

42. Purves, R. D. 1992. Optimum numerical integration methods for estimation of area-under-the-curve (AUC) and area-under-the-moment-curve (AUMC). J. Pharmacokinet. Biopharm. 20: 211-226. [Medline] [CrossRef]

43. Sakai, D. M., Martin-Flores, M., Romano, M., Tseng, C. T., Campoy, L., Gleed, R. D. and Cheetham, J. 2017. Recovery from rocuronium-induced neuromuscular block was longer in the larynx than in the pelvic limb of anesthetized dogs. Vet. Anaesth. Analg. 44: 246-253. [Medline] [CrossRef]

44. Sakai, D. M., Romano, M., Tseng, C. T., Flanders, A. and Martin-Flores, M. 2018. Bias, limits of agreement, and percent errors between acceleromyography and mechanomyography in anesthetized dogs. Vet. J. 233: 3-7. [Medline] [CrossRef]

45. Sparr, H. J., Wierda, J. M. K. H., Proost, J. H., Keller, C. and Khuenl-Brady, K. S. 1997. Pharmacodynamics and pharmacokinetics of rocuronium in intensive care patients. Br. J. Anaesth. 78: 267-273. [Medline] [CrossRef]

46. Steffey, E. P., Mama, K. R. and Brosnan, R. J. 2015. Inhalation anesthetics. pp. 297-323. In: Lumb and Jones' Veterinary Anesthesia and Analgesia, 5th ed. (Grimm, A, K., Lamont, L, A., Tranquilli, W, J., Greene, S, A and Robertson, S, A. eds.), John Wiley \& Sons, Inc., Ames.

47. Tseng, C. T., Sakai, D. M., Libin, M., Mostowy, M., Cheetham, J., Campoy, L., Gleed, R. D. and Martin-Flores, M. 2017. Partial neuromuscular block impairs arytenoid abduction during hypercarbic challenge in anesthetized dogs. Vet. Anaesth. Analg. 44: 1049-1056. [Medline] [CrossRef]

48. Viby-Mogensen, J., Jensen, E., Werner, M. and Nielsen, H. K. 1988. Measurement of acceleration: a new method of monitoring neuromuscular function. Acta Anaesthesiol. Scand. 32: 45-48. [Medline] [CrossRef]

49. Whittem, T., Beths, T. and Bauquier, S. B. 2015. General pharmacology of anesthetic and analgesic drugs. pp. 147-174. In: Lumb and Jones' Veterinary Anesthesia and Analgesia, 5th ed. (Grimm, A, K., Lamont, L, A., Tranquilli, W, J., Greene, S, A. and Robertson, S, A. eds.), John Wiley \& Sons, Inc., Ames.

50. Yamashita, K., Iwasaki, Y., Umar, M. A. and Itami, T. 2009. Effect of age on minimum alveolar concentration (MAC) of sevoflurane in dogs. J. Vet. Med. Sci. 71: 1509-1512. [Medline] [CrossRef] 